\title{
The effect of doping with pt impurity on ti clusters: a density functional theory study
}

TM Phaahla, ${ }^{a}$ PE Ngoepe, ${ }^{a}$ RA Catlow, ${ }^{a, b}$ HR Chauke ${ }^{a}$

\author{
aMaterials Modelling Centre, School of Physical and Mineral Sciences, University of Limpopo, Private bag X1106, Sovenga 0727, South Africa \\ 'University College London, Kathleen Lonsdale Materials Chemistry, Department of Chemistry, 20 Gordon Street, London WC1H OAJ, \\ United Kingdom \\ Email: phaahla.tshegofatso@ul.ac.za
}

\begin{abstract}
Transition metal nanoclusters have been greatly investigated in various areas such as catalysis, energy conversion and sensing due to their unique chemical, optical, structural, and electronic properties. Doping monometallic clusters with other metals offer the opportunity to enhance these properties. Extensive work has been done on late transition metal clusters i.e., noble and platinum metals. However, less work has been done on titanium metal clusters. The structural properties of $\operatorname{Ti}_{\mathrm{N}-1} \mathrm{Pt}(\mathrm{N}=2-16)$ clusters have been investigated using the density functional theory method with the PBEsol exchange-correlation functional. Our results showed that the binding energies for both systems decrease with cluster size $\mathrm{N}$. The $\mathrm{Ti}_{12} \mathrm{Pt}$ cluster was found to be more enhanced in comparison with pure Ti revealed by the binding energy, relative stability and dissociation energy. Furthermore, binding, relative stability and dissociation energies were found to be enhanced as compared to the energies for Ti monometallic clusters.
\end{abstract}

\section{Introduction}

Titanium possesses the unfilled $3 \mathrm{~d}^{2}$ shell that makes it available for physical and chemical properties from the low-lying electronic states and spin multiplicities [Du et al. 2010]. Several theoretical studies have been performed on the pure Ti clusters [Du et al. 2010, Castro et al. 2003, Wei et al. 2000]. Castro et al. (2003) used the generalized gradient approximation (GGA) to study the structures and spectroscopy of $\mathrm{Ti}_{\mathrm{N}}$ and $\mathrm{Ti}_{\mathrm{N}}(\mathrm{N}=3-8,13)$, the calculated density of states (DOS) and adiabatic binding energies for the ground state. It was found that the clusters possess highly compact structures, and $\mathrm{Ti}_{7}$ and $\mathrm{Ti}_{13}$ have distorted pentagonal bi-pyramid and icosahedra as magic isomers. Density functional theory with local spin density approximation (LSDA) was used by Wei et al. (2000) to study the $\mathrm{Ti}_{\mathrm{N}}(\mathrm{N}=2-10)$ clusters and obtained the magic number at $\mathrm{N}=7$. Tomas et al. (2018) used density functional theory to investigate the thermodynamics accessible titanium, $\mathrm{N}=2-32$. They reported $\mathrm{Ti}_{7}$ and $\mathrm{Ti}_{13}$ as the magic clusters.

The bimetallic clusters have been extensively investigated since the additive effect of the second metallic component in the bimetallic system due to their significant role in catalytic properties, surface segregations, etc., that emerges from the combination of nanosystems with different transition metal species [Batista et al. 2018]. However, not much has been done for the Ti-bearing bimetallic clusters. Al-doped Ti clusters in the DFT framework have been studied by Xiang et al. (2004) and reported the $\mathrm{Ti}_{4} \mathrm{Al}$ cluster as the magic cluster. They also reported that the valent transition of the $\mathrm{Al}$ atom is associated with the structural transfer commenced with $\mathrm{Ti}_{10} \mathrm{Al}$. Recently, small TM-doped Ti clusters ( $\mathrm{TM}=\mathrm{V}, \mathrm{Fe}$, $\mathrm{Ni}$ ) have been investigated [Du et al. 2009] to gain insight into the geometrical structures, chemical bonds and magnetic properties of these doped clusters. Previous research reported that the doping of the Fe [Sun et al. 1996] and Ni [Deshpande et al. 2005] clusters with boron increases the binding energies, however, decreases the magnetic moments of clusters. In this study, we investigate the effect of Pt impurity when doped on the titanium clusters to probe into the geometrical and stability of the $\mathrm{Ti}_{\mathrm{N}-1} \mathrm{Pt}$ clusters. Additionally, the $\mathrm{Ti}_{\mathrm{N}}$ clusters are also presented for comparison.

\section{Computational methodology}

Calculations in this work were carried out using the KnowledgeLed Master Code (KLMC) software suite [Woodley (2013), Farrow et al. 2014] and its recently improved genetic algorithm (GA) module, [Lazauskas et al. 2017] which has proved to locate efficiently local (LM) and global (GM) minima on PES. The PES of $\mathrm{Ti}_{\mathrm{N}}$ nanoclusters is evaluated using a many-body embedded atom method (EAM), which includes a combination of a many-body attractive term, $\mathrm{E}_{\mathrm{a}}$, and a repulsive two-body Born-Mayer IP, $\mathrm{E}_{\mathrm{r}}$.

$$
\begin{array}{ll}
E_{a}=-\sum_{i}\left(A \sum_{j} e^{-\beta\left(\frac{r_{i j}}{r_{0}-1}\right)}\right)^{\frac{1}{2}}, & 1 \\
E_{r}=\sum_{i>j} B e^{-\rho r_{i j}} & 2
\end{array}
$$

where $B$ and $A$ are empirical parameters; $r_{0}$ is the equilibrium first neighbour distance in hcp solid; $r_{i j}$ represents the distance between atoms $i$ and $j$. After completing the search on the IP PES, we have selected for refinement a subset of the lowest energy LM within approximately $1.0 \mathrm{eV}$ energy range above the corresponding tentative GM. The selected clusters were re-optimised at the quantum mechanical, DFT level using the all-electron, full potential electronic structure code FHI-aims [Blum et al. 2009]. Additionally, FHI-aims was further used to evaluate the effect of substituting one Ti atom with Pt impurity. 


\section{Results and discussion}

\section{Structure and characterization for $\mathbf{T i}_{\mathrm{N}-1} \mathbf{P t}$.}

The most energetic favoured isomers for $\mathrm{Ti}_{\mathrm{N}-1} \mathrm{Pt}$ clusters obtained by the FHI-aims technique are presented in figure 1 . The $\mathrm{N}=3$ cluster was an isosceles isomer that was observed to have $\mathrm{Pt}$ impurity capping on the $\mathrm{Ti}_{2}$ isomer. This position was observed to be mostly energetically favoured compared to others. At $\mathrm{N}=4$, the Pt atom was found to be more stable on the capped atom of the isosceles isomer or the Pt atom caps the surface of the three equilateral triangle $\mathrm{Ti}$ atoms.

The $\mathrm{N}=5$ cluster was observed to be a triangular bi-pyramidal configuration which is a $1-3-1$ layered stacking and the Pt atom staying at $1-2(\mathrm{Pt})-1$ layer. This is a face capped isomer with $\mathrm{Pt}$ atom capped on the opposite and adjacent faces of $\mathrm{Ti}$ atoms.

The octahedral isomer $\mathrm{N}=6$ is $1-4-1$ layered stacking where $\mathrm{Pt}$ atom is placed at $1-3(\mathrm{Pt})-1$ layered. This configuration also has the Pt impurity capped on the face. For $\mathrm{N}=7$, the pentagonal bi-pyramidal isomer is $1-5-1$ layered stacking and the Pt atom was favoured at $\mathrm{Pt}-5-1$ layer. This isomer was observed to have its impurity staying on the apex and the surface. The $\mathrm{N}=8$ cluster was a capped pentagonal bi-pyramid which was observed to have Pt atom placed on the capped atom of the pentagonal bipyramid or the $\mathrm{Pt}$ atom forming part of the pentagonal ring.

For $\mathrm{N}=9$, Pt atom was found to be placed on the apex of the Two-faced capped pentagonal. The $\mathrm{N}=10$ was observed to have its atom on the apex replaced with Pt atom. Similar observations were found for $\mathrm{N}=9$. The $\mathrm{N}=11$ was found to be a $1-5-1-4$ layered stacking where $\mathrm{Pt}$ atom is placed on the $1-5-1-3(\mathrm{Pt})$ layered stack. Pt atom was placed on one of the tetra atoms which are capped on the pentagonal bi-pyramid. For $\mathrm{N}=12$ the most favoured substituting is observed at $1-4(\mathrm{Pt})-1-4-1$ layered stacking.

The Pt atom is capped on the face of the pentagonal bi-pyramid.
The Z12 Frank-Casper polyhedral or icosahedral isomer is a $1-5$ $-1-5-1$ layered stacking and the Pt atom was found to be more stable at $1-4(\mathrm{Pt})-1-5-1$ layered stacking. The Pt impurity was placed on this precursor similarly with $\mathrm{N}=12$. The $\mathrm{N}=14$ is a Z13 Frank Casper polyhedral isomer which has the Pt atom staying at $1-5-1-5(\mathrm{Pt})-1$ layered stacking.

The Pt atom was capped on the pentagon ring. The Z14 Frank Casper polyhedral was found to have the most favoured site at $1-5$ $-1-6-1(\mathrm{Pt})$. Here, the Pt atom was observed to be placed on one of the two atoms which are capped on the apex of the pentagonal geometry. For $\mathrm{N}=16$, the $\mathrm{Z} 15$ Frank Casper polyhedral is a $1-6$ $-1-7-1$ layered stacking and the Pt impurity placed at $1-6-1$ $-7-\mathrm{Pt}$. The Pt atom was observed to be placed on the atom which was capped on the Z14 Frank Casper polyhedral.

\section{Structural stability}

We focus on the changes in stability after introducing Pt impurity in titanium clusters. Figure 2 shows the ground state energy values for both $\mathrm{Ti}_{\mathrm{N}}$ and $\mathrm{Ti}_{\mathrm{N}-1} \mathrm{Pt}$ clusters $(\mathrm{N}=2-16)$. These are compared to distinctly gain insights into the change in the stability trend at various cluster sizes. The energy values of the binding energy $\left(\mathrm{E}_{\mathrm{b}}\right)$ are estimated with the following equations:

$$
\begin{aligned}
& E_{b}=\frac{E_{\text {cluster }}\left[T i_{N}\right]-N E_{\text {atom }}[T i]}{N} \\
& E_{b}= \\
& \frac{E_{\text {cluster }}\left[T i_{N-1} P t\right]-(N-1) E_{\text {atom }}[T i]-E_{\text {atom }}[P t]}{N}
\end{aligned}
$$

for $\mathrm{Ti}_{\mathrm{N}}, \mathrm{Ti}_{\mathrm{N}-1} \mathrm{Pt}$ clusters, where, and are the lowest energies of cluster and atom. The binding energies of the $\mathrm{Ti}_{\mathrm{N}-1} \mathrm{Pt}$ and $\mathrm{Ti}_{\mathrm{N}}$ clusters followed similar trends. Their binding energies decreases as the cluster size $\mathrm{N}$ increases. With sizes $\mathrm{N}=2-16, \mathrm{Ti}_{\mathrm{N}}$ clusters showed larger binding energies as compared to $\mathrm{Ti}_{\mathrm{N}-1} \mathrm{Pt}$ clusters. This observation revealed more stable relative energies to the $\mathrm{Ti}_{\mathrm{N}-1} \mathrm{Pt}$ clusters. The enhancement of the binding energies was
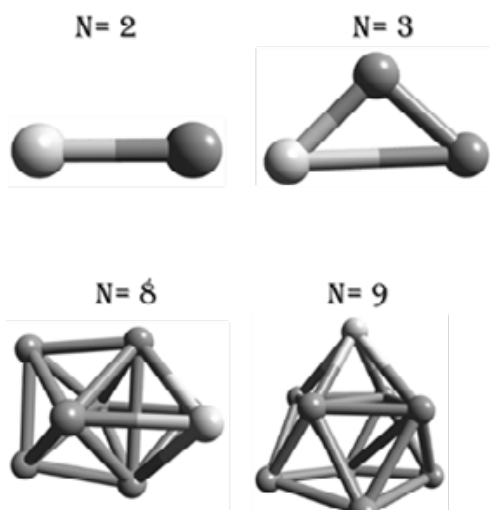
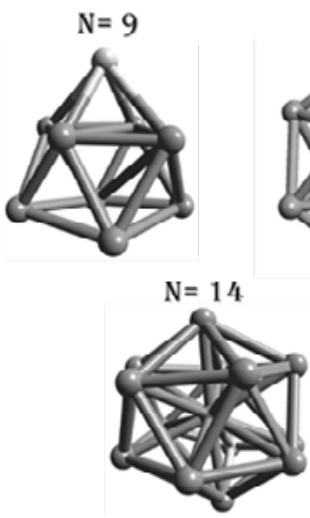

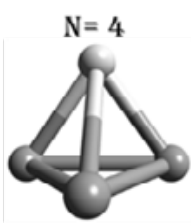

$\mathrm{N}=10$
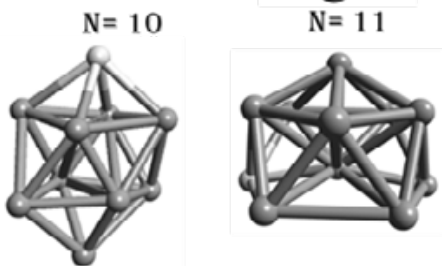

$\mathrm{N}=16$
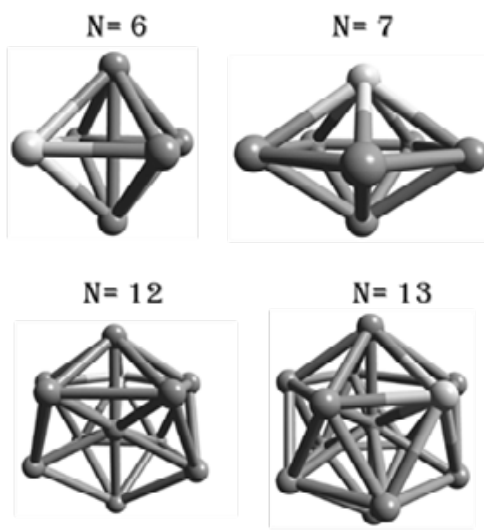
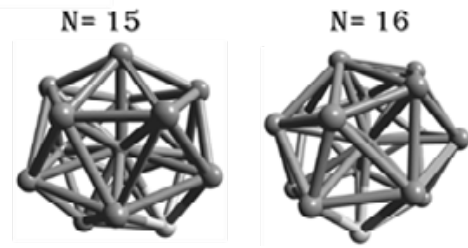

Figure 1: Putative global minimisation clusters obtained by DFT-PBESol calculation for the bimetallic $\mathrm{Ti}_{\mathrm{N}-1} \mathrm{Pt}(\mathrm{N}=2-16)$ clusters, where light atom represent $\mathrm{Pt}$ and grey atoms are $\mathrm{Ti}$ 
observed to reduce from $\mathrm{N}=7-16$. This behaviour was ascribed to the increase in $\mathrm{Ti}_{\mathrm{N}-1} \mathrm{Pt}$ coordination which weakens the interactions between $\mathrm{Ti}$ and $\mathrm{Pt}$ atoms [Du et al. 2010]. Furthermore, for $\mathrm{Ti}_{12} \mathrm{Pt}$ $(\mathrm{N}=13), \mathrm{Ti}_{7}(\mathrm{~N}=7)$ and its neighbours, the binding energy was slightly lowered while for $\mathrm{N}=15$ onwards the nanocluster become more stable.

The increase in the stability of the $\mathrm{Ti}_{12} \mathrm{Pt}$ and $\mathrm{Ti}_{7}$ clusters can be understood by the nature of the pentagonal and icosahedral structures. The high stability of the regular pentagonal and icosahedral structures usually occurs for transition-metal clusters due to their $\{111\}$ surface facets. This behaviour was also reported by Rodríguez-Kessler and Rodríguez-Domínguez (2016) and it was found that the icosahedral structure possesses a special reactivity when compared to the less coordinated neighbouring structures. The second-order energy $\mathrm{D}_{2} \mathrm{E}$ (relative stability) and dissociation energy were used to determine the stability of $\mathrm{Ti}_{\mathrm{N}-1} \mathrm{Pt}$ and $\mathrm{Ti}_{\mathrm{N}}$ clusters (figure 3 ). Higher stability was associated with the lower negative value in energy that was ascribed to favourable nucleation. In figure 3(a), the relative stability is estimated with the following equations:

$$
D_{2} E\left[T i_{N}\right]=E_{T}\left[T i_{N+1}\right]+E_{T}\left[T i_{N-1}\right]-2 E_{T}\left[T i_{N}\right] 5
$$

for pure $T \mathrm{Ti}_{\mathrm{N}}$ clusters, and

$$
\begin{aligned}
& D_{2} E\left[T i_{N} P t\right]=E_{T}\left[T i_{N+1} P t\right]+E_{T}\left[T i_{N-1} P t\right]- \\
& 2 E_{T}\left[T i_{N} P t\right]
\end{aligned}
$$

for the Pt-doped $\mathrm{Ti}_{\mathrm{N}}$ clusters, where $\mathrm{E}_{\mathrm{T}}[\mathrm{Ti}], \mathrm{E}_{\mathrm{T}}[\mathrm{Pt}]$, and $\mathrm{E}_{\mathrm{T}}\left[\mathrm{Ti}_{\mathrm{N}} \mathrm{Pt}\right]$ are the total energies of the bare $\mathrm{Ti}$ atom, the Pt atom, and the $\mathrm{Ti}_{\mathrm{N}} \mathrm{Pt}$ doped cluster, while $\mathrm{N}$ denotes the number of $\mathrm{Ti}$ atoms in the cluster, respectively. As shown in figure 3, the $\mathrm{N}=5$ and $\mathrm{N}=$ 7 clusters with the lowest relative values have stronger stabilities as compared to their neighbouring clusters. This is in excellent agreement with the previous report [Du et al. 2010].

The $\mathrm{Ti}_{\mathrm{N}-1} \mathrm{Pt}$ plot showed distinct peaks at $\mathrm{Ti}_{12} \mathrm{Pt}$ and $\mathrm{Ti}_{6} \mathrm{Pt}$ respectively. This observation indicates stronger stability for $\mathrm{Ti}_{12} \mathrm{Pt}$ and $\mathrm{Ti}_{6} \mathrm{Pt}$ clusters than their neighbouring clusters. It was clearly seen that the Pt impurity enhanced the $\mathrm{Ti}_{13}$ energy in comparison with the pure $\mathrm{Ti}_{13}$ cluster. These magic clusters correlate to triangular bi-pyramid, pentagonal bi-pyramid, icosahedron and Z14 FrankKasper polyhedron. To further confirm the relative stabilities of $\mathrm{Ti}_{5}, \mathrm{Ti}_{7}, \mathrm{Ti}_{12} \mathrm{Pt}$ and $\mathrm{Ti}_{6} \mathrm{Pt}$ clusters, we evaluated the dissociation

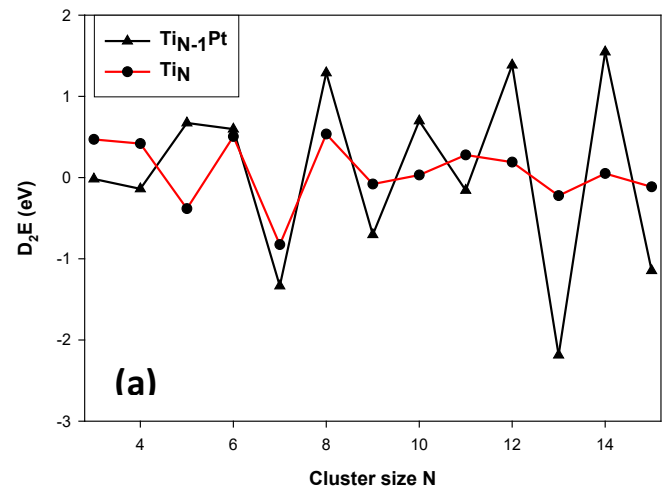

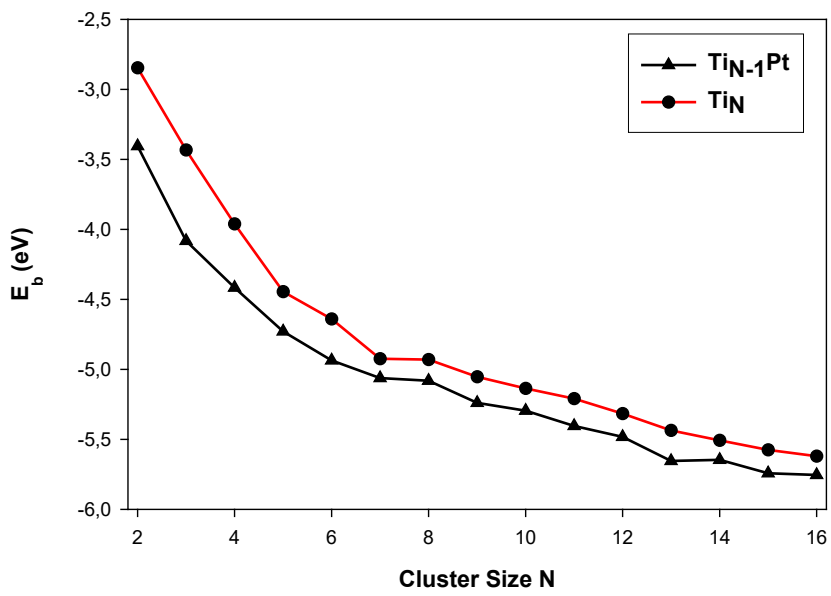

Figure 2: The binding energies per atom $\left(\mathrm{E}_{\mathrm{b}} /\right.$ atom $)$ of the $\mathrm{Ti}_{\mathrm{N}}$ and $\mathrm{Ti}_{\mathrm{N}-1} \mathrm{Pt}$ clusters with $\mathrm{N}=2-16$

energies which are plotted in figure 3 (b). The dissociation energies are estimated with the following equations:

$$
\begin{aligned}
& E_{d}\left[T i_{N-1} P t\right]=E\left[T i_{N-1} P t\right]-E\left[T i_{N-2} P t\right]- \\
& E[T i]
\end{aligned}
$$

for one Ti dissociation and

$$
\begin{aligned}
& E_{d}\left[T i_{N-1} P t\right]=E\left[T i_{N-1} P t\right]-E\left[T i_{N-3} P t\right]- \\
& E\left[T i_{2}\right]
\end{aligned}
$$

for $\mathrm{Ti}_{2}$ dissociation

and

$$
E_{d}=E_{N}-E_{N-1}-E_{1}
$$

for pure Ti.

The highest energy dissociation peaks correspond to the loss of Ti atoms in both channels. For pure $\mathrm{Ti}_{\mathrm{N}}$ clusters, $\mathrm{N}=5$ and $\mathrm{N}=7$ still showed lower energy channels, however, the $\mathrm{N}=13$ cluster showed the lowest energy channels, contrary to the relative energies. In the case of Ti-doped clusters, $\mathrm{Ti}_{12} \mathrm{Pt}$ still represented the lowest dissociation energies suggesting high stabilities. However, the $\mathrm{Ti}_{14} \mathrm{Pt}$ cluster was found to have replaced the $\mathrm{Ti}_{6} \mathrm{Pt}$ cluster as the meta-stable cluster.

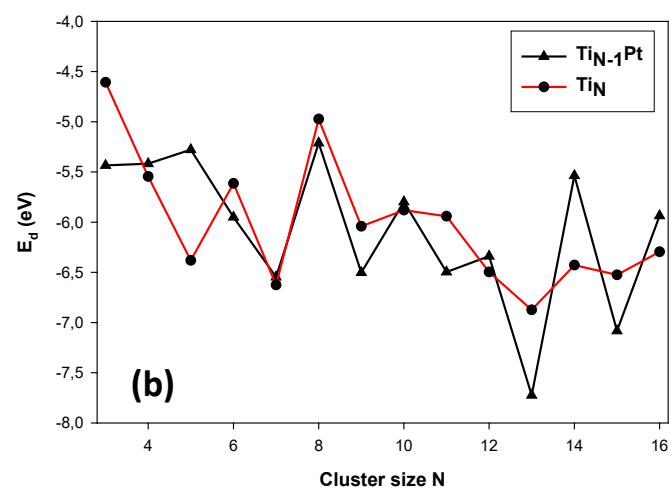

Figure 3: (a) The relative stability $\left(\mathrm{D}_{2} \mathrm{E}\right)$ and (b) dissociation energy $\left(\mathrm{E}_{\mathrm{d}}\right)$ of $\mathrm{Ti}_{\mathrm{N}}$ and $\mathrm{Ti}_{\mathrm{N}-1} \mathrm{Pt}$ clusters with $\mathrm{N}=2-16$ 


\section{Conclusion}

The density functional theory approach was used to investigate the changes in the stabilities of $\mathrm{Ti}_{\mathrm{N}}(\mathrm{N}=2-16)$ clusters as one Ti atom was substituted by Pt impurities. For Z12 Frank-Casper polyhedral or icosahedral geometry, the Pt atom prefered to be located at $1-4(\mathrm{Pt})-1-5-1$ layered stacking. The doping of Pt atom enhanced the stabilities of titanium clusters in terms of binding energies, relative energies and dissociation energies. The $\mathrm{Ti}_{5}, \mathrm{Ti}_{7}, \mathrm{Ti}_{6} \mathrm{Pt}$ and $\mathrm{Ti}_{12} \mathrm{Pt}$ presented higher stabilities as compared to their neighbouring clusters.

\section{Author contributions}

T. M. P and H. R. C prepared the manuscript, constructed the models and analytical tools. T. M. P performed the calculations using the PBEsol level of theory. T. M. P and H. R. C analysed the results. C. R. A. C., H. R. C. and P. E. N. formulated the project.

\section{Acknowledgements}

The research is part of the collaboration between the groups of H.R.C. and P.E.N. University of Limpopo (UL) and C.R.A.C, A. A. S and S.M.W. University College London (UCL). This work made use of the facilities of Materials Modelling Centre (MMC), University of Limpopo, UCL Faraday and UCL Research computing platforms services, the Centre for High-Performance Computing (CHPC). The authors wish to recognize the support of the South African Research Chair initiative of the Department of Science and Technology and the National Research Foundation. The authors would also like to acknowledge the financial support of the Department of Science and Innovation (DSI), through the Titanium Competency Centre (TiCoC) of the Advanced Materials Initiative (AMI). The support of the South African Research Chair initiative of the Department of Science and Innovations is highly appreciated.

\section{References}

1. Du J., Sun X., Chen J., Jiang G., 2010. The changes in the geometrical, electronic and magnetic properties of titanium clusters as one titanium atom is substituted by boron. Journal of Physics B: Atomic, Molecular and Optical Physics, 43, 205103.

2. Castro M., Liu S.R., Zhai H.J., Wang L S., 2003. Structural and electronic properties of small titanium clusters: A density functional theory and anion photoelectron spectroscopy study. The Journal of Chemical Physics 118, 2116.

3. Wei, S.H., Zeng, Z., You, J.Q., Yan, X.H., Gong, X.G., 2000. A density-functional study of small titanium clusters. The Journal of Chemical Physics, 113, 11127.

4. Lazauskas, T., Sokol, A.A., Buckeridge, J., Catlow, C.R.A., Escher, S.G.E.T., Farrow, M.R., Mora-Fonz, D., Blum, V.W., Phaahla, T.M., Chauke, H.R., Ngoepe, P.E., Woodley, S.M., 2018. Thermodynamically accessible titanium clusters $\mathrm{Ti}_{\mathrm{n}}, \mathrm{n}=2-32$. Journal of Physical Chemistry Chemical Physics, 20, 13962.

5. Batista, K.E.A., Da Silva, J.L.F., Piotrowski, M.J., 2018. Ab Initio Investigation of the Role of Atomic Radius in the Structural Formation of $\mathrm{Pt}_{\mathrm{n}} \mathrm{TM}_{55-\mathrm{n}}(\mathrm{TM}=\mathrm{Y}, \mathrm{Zr}, \mathrm{Nb}, \mathrm{Mo}$, and $\mathrm{Tc})$ Nanoclusters. The Journal of Physical Chemistry C, 122, 7444-7454.

6. Xiang, J., Wei, S.H., Yan, X.H., You., J.Q., Mao, Y.L., 2004. A densityfunctional study of Al-doped Ti clusters: $\mathrm{Ti}_{\mathrm{n}} \mathrm{Al}(\mathrm{n}=1-13)$ The Journal of Chemical Physics 120, 4251.

7. Du, J.G., Sun, X.Y., Jiang, G., 2009. A DFT study on small M-doped titanium $(\mathrm{M}=\mathrm{V}, \mathrm{Fe}, \mathrm{Ni})$ clusters: structures, chemical bonds and magnetic properties. European Physical Journal D, 55, 111.

8. Sun, Q., Gong, X.G., Zheng, Q.Q., Wang, G.H ., 1996. The structures and magnetic properties of small $\mathrm{Fe}_{\mathrm{n}} \mathrm{B}$ clusters. Journal of Physics: Condensed Matter, 8, 1805.

9. Deshpande, M., Kanhere, D.G., Pandey, R., 2005. Structures, energetics, and magnetic properties of $\mathrm{Ni}_{\mathrm{n}} \mathrm{B}$ clusters with $\mathrm{n}=1-8,12$. Journal of Physical Review A, 71, 063202.

10. Woodley, S.M., 2013. Knowledge Led Master Code Search for Atomic and Electronic Structures of $\mathrm{LaF}_{3}$ Nanoclusters on Hybrid Rigid IonShell Model-DFT Landscapes. The Journal of Physical Chemistry, C 117, 24003-24014.

11. Farrow, R.M., Chow, Y., Woodley, S.M., 2014. Structure prediction of nanoclusters; a direct or a pre-screened search on the DFT energy landscape?. Journal of Physical Chemistry Chemical Physics, 16 , 21119-21134.

12. Lazauskas, T., Sokol, A.A., Woodley, S.M., 2017. An efficient genetic algorithm for structure prediction at the nanoscale. Journal of Nanoscale, 9, 3850-3864.

13. Blum, V., Gehrke, R., Hanke, F., Havu, P., Havu, V., Ren, X., Reuter, K., Scheffler, M., 2009. Ab initio molecular simulations with numeric atom-centered orbitals. Journal of Computer Physics Communications, 180, 2175-2196.

14. Rodríguez-Kessler, P.L., Rodríguez-Domínguez, A.R., 2016. Structures and Electronic Properties of $\mathrm{Ti}_{\mathrm{n}} \mathrm{V}(\mathrm{n}=1-16)$ Clusters: First-Principles Calculations. The Journal of Physical Chemistry, A 120, 2401-2407. 